This paper is published in the open archive of Mid Sweden University

DIVA http://miun.diva-portal.org

with permission of the publisher

Citation for the peer-reviewed published paper:

Andersson K, Pranovich A, Norgren M, Eriksson M, Holmbom B. Effects of biological treatment on the chemical structure of dissolved lignin-related substances in effluent from thermomechanical pulping. ; Nordic Pulp \& Paper Research Journal. 2008;23(2):164-171.

URL to article at publishers site:

http://dx.doi.org/10.3183/NPPRJ-2008-23-02-p164-171 


\title{
Effects of biological treatment on the chemical structure of dissolved lignin-related substances in effluent from thermomechanical pulping
}

\begin{abstract}
Kerstin I. Andersson, Mid Sweden University and SCA R\&D Centre, Sundsvall, Sweden, Andrey V. Pranovich, Åbo Akademi University, Turku/Åbo, Finland, Magnus Norgren, Mid Sweden University, Marie Eriksson, SCA R\&D Centre, Sundsvall, Sweden, Bjarne Holmbom, Åbo Akademi University, Turku/Åbo, Finland
\end{abstract}

KEYWORDS: Wastewater treatment, Biodegradability, Thermomechanical pulping, Lignin, COD, Chromatography, Spectrometry.

\begin{abstract}
SUMMARY: Effluent from a TMP-based pulp and paper mill was collected at the inlet and outlet of the mill's biological treatment plant and fractionated by sorption on XAD- 8 resin and MTBE precipitation. Fractionation indicated that the refractory dissolved organic material in biologically treated effluent was mainly composed of lignin-related substances. Characterisation of the lignin-related substances by chromatographic and spectrometric methods confirmed the similarities of the isolated material and milled wood lignin. Fractionation and characterisation of alkali-extracted material from solids (biosludge) in biologically treated effluent found evidence of lignin-related material. Results indicated that biological treatment had altered the chemical structure and molar-mass distribution of dissolved lignin-related substances.
\end{abstract}

\footnotetext{
ADDRESSES OF THE AUTHORS: Kerstin Andersson (kerstin.andersson.x@sca.com) and Marie Eriksson (marie.eriksson@sca.com): SCA R\&D Centre, Box 716, SE-851 21 Sundsvall, Sweden. Magnus Norgren (magnus. norgren@miun.se): Mid Sweden University, Fibre Science and Communication Network, FSCN, SE-851 70 Sundsvall, Sweden. Andrey Pranovich (apranovi@abo.fi) and Bjarne Holmbom (bjarne.holmbom@abo.fi): Åbo Akademi University, Process Chemistry Centre, Laboratory of Wood and Paper Chemistry, Porthansagatan 3, FI-20500 Turku/Åbo, Finland. Corresponding author: Kerstin Andersson
}

Trends in today's pulp and paper sales market indicate a growing demand for high-brightness products with subsequent need of peroxide-bleached mechanical pulp. Thermomechanical pulping and alkaline peroxide bleaching generate wastewater containing considerable amounts of wood-derived pollutants (Widsten and Laine 2003; Thompson et al. 2001). In processing wood into thermomechanical pulp (TMP), between 3 and $5 \%$ of the wood is lost (Holmbom et al. 2005; Manner et al. 1999; Rintala and Puhakka 1994). Bleaching with alkaline hydrogen peroxide causes material losses of the same magnitude as does the pulping itself (Lindholm 1999; Manner et al. 1999). The released material includes carbohydrates, low-molar-mass organic acids, pectic acids, lignans, lipophilic extractives, and lignin-related substances (Thornton 1993). Generated wastewater containing released material is traditionally characterised with regards to environmental impact by chemical oxygen demand (COD), biochemical oxygen demand (BOD), total organic carbon (TOC), suspended solids, toxicity, and colour (Pokhrel and Viraraghavan 2004; Widsten and Laine 2003). Upon discharge of wastewater, the released dissolved and colloidal compounds contribute in varying amounts to the consumption of oxygen in the receiving waters (Magnus et al. 2000). When a recipient becomes deficient in dissolved oxygen it loses its ability to support life, threatening the survival of plants and animals (Smook 2002). Secondary biological treatment is therefore normally applied to effluents from pulp and paper production, thereby significantly reducing the discharge of oxygen-consuming substances (Widsten and Laine 2003; Thompson et al. 2001; Springer 1993). Treated effluent, however, still contains various compounds that are difficult to remove by biological treatment. One such group of compounds is lignin-related substances, which persist despite the treatment and contribute significantly to the COD of the treated wastewater (Widsten and Laine 2003; Smook 2002; Helmreich et al. 2001; Magnus et al. 2000; Franta et al. 1994). Growing demand for high brightness products has prompted the extensive use of bleaching chemicals (Lindholm 1999). A study of mechanical pulp and bleaching processes (Pranovich et al. 2003) has demonstrated that alkali treatment of spruce TMP, even without hydrogen peroxide, releases substantial amounts of lignin from the fibres. In the presence of hydrogen peroxide, oxidation leads to further release of organic fibre components. From this it may be concluded that an increased release of recalcitrant compounds into the process waters can be expected when bleaching to high brightness.

Removal of lignin in biological effluent treatment plants has been subject to investigation (Widsten and Laine 2003; Helmreich et al. 2001; Magnus et al. 2000; Jansson 1980; Ganczarczyk and Obiaga 1973). Several authors ascribe lignin removal to a combination of partial degradation and sorption to the biomass in the treatment plant (Magnus et al. 2000; Helmreich et al. 2001; Levine et al. 1985; Ganczarczyk and Obiaga 1973). There is, however, little information on how, and to what extent, lignin-related substances are affected by the mechanisms in activated sludge treatment plants. In the present work, lignin-related material was isolated from wastewaters originating from the production of alkaline peroxide-bleached TMP. Wastewater samples before and after the mill's biological treatment plant were collected, and the isolated material was studied in detail by chemical characterisation in order to learn more about the fate of lignin in biological wastewater treatment.

The methods for quantifying and structurally determining complex polymers such as lignin are inherently difficult. Pyrolysis, in combination with gas chromatography (GC) and mass spectrometry (MS), gives information 
on the chemical structure of fragments. Solution and solid-state nuclear magnetic resonance (NMR) and Fourier-transform infrared spectrometry (FT-IR) provide information on the functional groups, and on the binding pattern and structure of the phenolic, monomeric constituents of polymers (Galletti and Bocchini 1995). Size-exclusion chromatography (SEC) is, like NMR and FT-IR, a non-destructive method (Galletti and Bocchini 1995) providing information on the molar mass average and distribution of polymers (Pranovich et al. 2005; Hoque 1995). No single technique provides complete structural information on its own, but when combined, the methods mentioned above provide an overview of the character of the polymer under study.

\section{Materials and Methods}

\section{Sampling}

Wastewater samples were collected at the Ortviken Paper Mill (Sundsvall, Sweden), an integrated TMP mill producing 850.000 tonnes/year of lightweight coated paper (LWC) and newsprint from Norway spruce. Of the produced TMP, 55\% is bleached using alkali and hydrogen peroxide. The wastewater samples were mixed effluent from the TMP plant, bleaching plant, paper machines, debarking, and sludge dewatering. During the time of sampling, the wastewater treatment plant received about $33.000 \mathrm{~m}^{3} /$ day of mixed effluent with a concentration of soluble COD of approximately $2000 \mathrm{mg} / \mathrm{l}$. The treatment plant consists of primary clarification, secondary biological treatment, and solids separation. The secondary biological treatment has a total hydraulic retention time of about five days and is comprised of a pre-treatment followed by an aerated lagoon. The pre-treatment is a three-step process with an aeration tank, a carrier system for attached growth of microorganisms (biofilm), and an activated sludge treatment. The overall removal of soluble COD was $88 \%$ at the time of sampling. Samples were taken of primary-treated effluent (PTE), finally-treated effluent (FTE), and separated solids (sludge). An outline of the treatment plant, showing sampling points, is given in Fig 1. Sludge samples were collected and dewatered by centrifugation. Remaining extracellular water was removed by washing with distilled water and centrifugation. The washing procedure was repeated twice. Adsorbed lignin-related material was extracted by diluting the washed sludge with distilled water and adjusting $\mathrm{pH}$ to 10 , using $\mathrm{NaOH}$. The samples were stirred for 60 min and then centrifuged to separate the solids. The extraction was repeated twice, and the supernatant liquors were mixed and stored at $5^{\circ} \mathrm{C}$. After this treatment, only a minor amount of lignin-related material could be extracted from the sludge, as could be seen from absorbance measurements at $280 \mathrm{~nm}$. The PTE and FTE samples were filtered through a 200 mesh nylon wire and centrifuged to remove solids before storage at $5^{\circ} \mathrm{C}$.

\section{Fractionation}

Fractionation of the wastewater samples was performed using the method previously described by Pranovich et al.

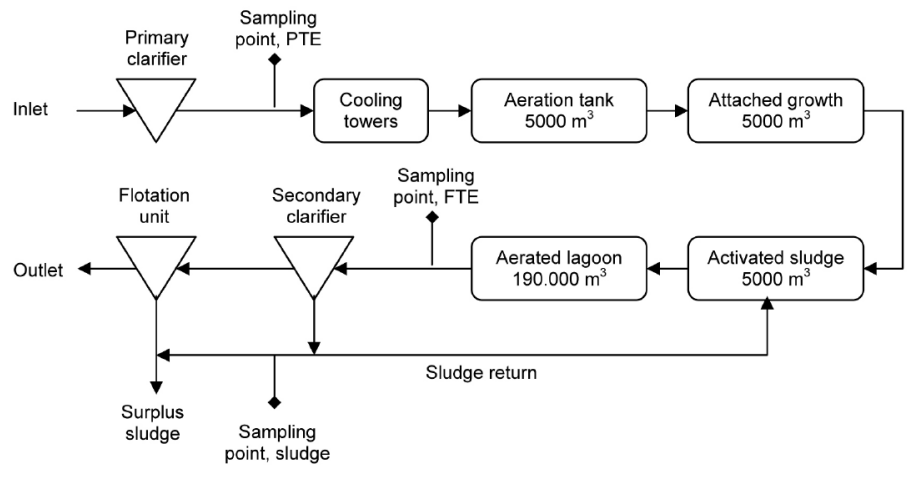

Fig 1. Outline of the effluent treatment plant and sampling points.

(2005) for use on TMP water. The samples were fractionated into hydrophilic and hydrophobic substances by sorption chromatography on Amberlite XAD-8 resin (Fluka Chemie, Buchs, Switzerland) after filtration through fibreglass filter GF 50 (Schleicher and Schuell, Dassel, Germany) and acidification to $\mathrm{pH} 2$. The hydrophobic fraction was eluted with methanol. The hydrophilic and hydrophobic fractions were neutralised with diluted $\mathrm{NaOH}$. After evaporating the solvent, the hydrophobic fraction was re-dissolved in a small volume of methanol and the insoluble material was separated. The methanolsoluble fraction was further separated into lignin-related material and oligomeric aromatic substances by means of multiple precipitation in methyl tert-butyl ether (MTBE). An outline of the fractionation procedure is shown in Fig 2.

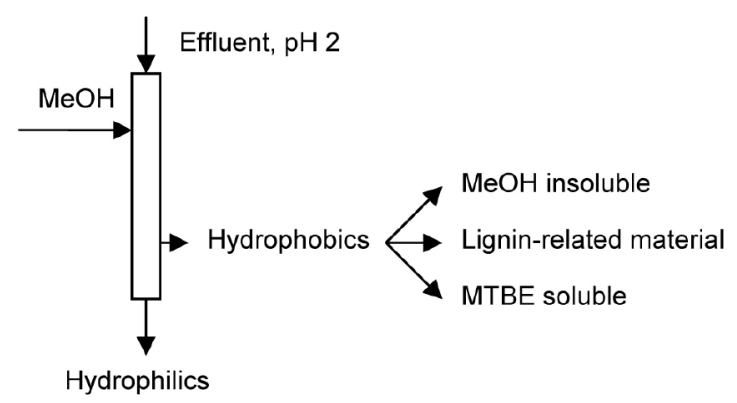

Fig 2. Outline of the fractionation procedure.

\section{Analyses}

Ash analyses were performed at $550^{\circ} \mathrm{C} \pm 25^{\circ} \mathrm{C}$ according to the ISO standard 1762 (2001).

The total organic carbon (TOC) of effluent samples was measured with a TOC-5050 analyser (Shimadzu Corp., Kyoto, Japan) on filtered samples according to the SS-EN 1484 standard (1997).

The carbohydrate content of the isolated lignin fractions was analysed by GC after methanolysis and silylation of the samples, using the method described in detail by Sundberg et al. (1996). A reference solution of sugars, also subjected to methanolysis, was used to estimate their correction coefficients and for identification using GC-MS; the identified monomers were arabinose, rhamnose, xylose, mannose, galactose, galacturonic acid, glucose, and glucuronic acid.

The extractives content was determined using GC and GC-MS. Group separation and the quantification of free fatty acids, resin acids, sterols, steryl esters, triglycerides, and lignans was done using GC with a short column 
according to the method described by Örså and Holmbom (1994). Using the method described by Ekman and Holmbom (1989), individual compounds were separated by GC with a long capillary column, and identified by GC-MS. Compounds were quantified and identified using internal standards.

GC-MS was performed on an HP 5890 GC (Hewlett Packard, Palo Alto, CA) equipped with an HP 5970 quadrupole mass selective detector (electron impact 70 $\mathrm{eV})$, using an HP-1 capillary column $(25 \mathrm{~m} \times 0.2 \mathrm{~mm}$ i.d., film thickness $0.11 \mu \mathrm{m}$ ) and helium as the carrier gas. The initial temperature was $60^{\circ} \mathrm{C}$ with an increase rate of $8^{\circ} \mathrm{C} / \mathrm{min}$ and the injector temperature was $260^{\circ} \mathrm{C}$.

Aqueous SEC (Aq-SEC) analyses were performed by STFI-Packforsk (Stockholm, Sweden) on a 515 HPLC pump (Waters Corp., Milford, MA) using a Separon S Hema 1000 column (250 x 8 mm i.d.; Tessek, Prague, Czech Republic) coated with hydroxyethyl methacrylate (film thickness $10 \mu \mathrm{m}$ ). Ammonium acetate was used as the mobile phase with a flow rate of $0.8 \mathrm{ml} / \mathrm{min}$, and the detector was a 2414 Refractive Index Detector (Waters Corp., Milford, MA). Molar mass was calculated relative to polystyrene standards.

Measurements of 1H PFG NMR self-diffusion coefficients were made on a Bruker Avance DPX $250 \mathrm{MHz}$ spectrometer equipped with a Bruker self-diffusion probe, capable of providing $18 \mathrm{~T} / \mathrm{m}$ at $60 \mathrm{~A}$ (Bruker Biospin AG, Karlsruhe, Germany). The samples were dissolved in $0.1 \mathrm{M} \mathrm{NaOD}$ to a concentration of $1 \mathrm{wt} \%$. Typically, the gradient strength (g) was varied from 0.4 to $2.0 \mathrm{~T} / \mathrm{m}$ for a duration of $\delta=1.0 \mathrm{~ms}$. The diffusion time was set to $\Delta=100 \mathrm{~ms}$ and 128 scans were accumulated at 17 different gradient strengths. As described by Håkansson et al. (2000), Garver and Callaghan (1991), and Fleischer (1985), the resulting self-diffusion coefficients of the lignin samples could be obtained after fitting the intensity decays $(I(k, D))$ to a lognormal distribution function

$I(k, D)=\int_{0}^{\infty} \frac{1}{D \sigma \sqrt{2 \pi}} \exp \left[-\left(\frac{\ln (D)-\ln \left(D_{m}\right)}{\sigma \sqrt{2}}\right)^{2}\right] \exp (-k D) d D$ [1]

where $D_{m}$ denotes the fitted mass-weighted median selfdiffusion coefficient, $\sigma$ describes the distribution width, $k$ is defined from the experimental settings as

$$
k=\gamma^{2} \delta^{2} g^{2}\left(\Delta-\frac{\delta}{3}\right)
$$

and $\gamma$ is the nuclear magnetogyric radius for protons. Sodium polystyrene sulfonate standards were used to obtain the scaling parameters $\left(K=1.62 \times 10^{-8} \mathrm{~m}^{2} / \mathrm{s}\right.$ and $\alpha$ $=-0.58)$ needed to calculate the mass-weighted molar mass distribution by applying the Mark-Houwink relationship between the self-diffusion coefficient $(D)$ and the molar mass $(M)$, i.e.

$$
D=K M^{\alpha}
$$

The number-average $\left(M_{n}\right)$ and weight-average $\left(M_{w}\right)$ molar mass, as well as the polydisperity index, were derived and calculated from the lognormal distribution according to Eqs 4-6.

$$
\begin{aligned}
& M_{n}=M_{m} \exp \left[\frac{1}{2}\left(\frac{\sigma}{\alpha}\right)^{2}\right] \\
& M_{w}=M_{m} \exp \left[\frac{3}{2}\left(\frac{\sigma}{\alpha}\right)^{2}\right] \\
& \frac{M_{w}}{M_{n}}=\exp \left(\frac{\sigma}{\alpha}\right)^{2}
\end{aligned}
$$

The absorption of ultraviolet (UV) radiation at $280 \mathrm{~nm}$ was measured on a Cary $100 \mathrm{UV}-\mathrm{Vis}$ spectrophotometer (Varian, Palo Alto, CA) on isolated lignin samples. Five $\mathrm{mg}$ of lignin was dissolved in distilled water to a concentration at which absorption readings were approximately 0.5 against a matching cuvet with distilled water. The absorptivity coefficients were calculated from the known concentrations of the dissolved lignin samples (Lin 1992).

The FT-IR analyses were performed on a Nicolet Magna 750 spectrometer (Nicolet, San Jose, CA) at the SCA R\&D Centre (Sundsvall, Sweden) on $\mathrm{KBr}$ tablets using a DTGS detector with a resolution of $4 \mathrm{~cm}^{-1}$.

Pyrolysis coupled with GC and MS (Py-GC-MS) was performed on a filament pulse Pyrola 85 pyrolyser (Pyrol AB, Lund, Sweden) using the GC-MS described above. The pyrolysis temperature was $650^{\circ} \mathrm{C}$ for $2 \mathrm{~s}$. For thermally-assisted hydrolysis and methylation (THM), 10\% aqueous tetramethylammonium hydroxide (TMAH) was added and the filament was heated at $360^{\circ} \mathrm{C}$ for $2 \mathrm{~s}$.

Qualitative ${ }^{13} \mathrm{C}$ NMR measurements were performed on a Bruker Avance DPX $500 \mathrm{MHz}$ spectrometer (Bruker Biospin AG, Karlsruhe, Germany) on samples dissolved in DMSO-d6. Typically, data from 30.000 scans, utilising a standard proton decoupled pulse sequence, were acquired.

\section{Results and Discussion}

In the literature there seems to be confusion regarding how to refer to lignin released from wood fibres during pulping processes. The three-dimensional structure of lignin in woody plants with a molar mass considered infinite (Smook 2002; Kringstad and Lindström 1984) may have limited similarities to the released lignin fragments found in process waters. This sometimes leads to incoherence when discussing the chemical characteristics of lignin. Here the term lignin is used to refer to lignin-related aromatic material having hydrophobic properties, not soluble in MTBE in accordance with the fractionation technique used.

\section{Quantitative analysis}

The quantitative evaluation of the fractionation of the primary-treated and finally-treated effluent samples is 
presented in Table 1 in terms of gravimetric results. The removal of only $27 \%$ of the hydrophilic fraction, expected to contain easily degradable substances such as hemicelluloses, pectin, and low-molar-mass acids, was explained by the high content of inorganic salts originating from bleaching processes and sample preparation. The removal efficiency of organic material in the hydrophilic fraction was, as expected, considerably higher, reaching $89 \%$. The hydrophobic fraction was further separated into substances rich in carbohydrates insoluble in methanol, and another fraction soluble in methanol. Substances soluble in methanol were finally divided into oligomeric aromatic substances, mainly composed of low-molar-mass extractives soluble in MTBE, and lignin-related substances. The removal of methanol-insoluble material was poor, but the residual amount in treated wastewater was small so the contribution to COD should be moderate. The MTBE-soluble substances had a high removal efficiency (92\%), and small amounts in the treated effluent suggest that these extractives are successfully removed in the treatment plant. In accordance with the previously discussed low biodegradability of lignin-related material, the lignin fraction appeared to have a rather low removal efficiency of $65 \%$. In combination with the relatively large amounts of residual lignin-related material in treated effluent, this implies that lignin-derived compounds are a major contributor to COD in treated effluent.

Table 1. Gravimetric evaluation of fractionation and removal due to biological treatment calculated as the percentage decrease in the FTE sample compared to the initial concentration in the PTE sample. Sample notations: primary-treated effluent (PTE) and finally-treated effluent (FTE).

\begin{tabular}{lccc}
\hline Fractions & $\begin{array}{c}\text { PTE } \\
\mathrm{mg} / \mathrm{l}\end{array}$ & $\begin{array}{c}\text { FTE } \\
\mathrm{mg} / \mathrm{l}\end{array}$ & $\begin{array}{c}\text { Removal } \\
\%\end{array}$ \\
\hline Total hydrophilics $^{\text {Organic material }}{ }^{1}$ & 2848 & 2089 & 27 \\
Total hydrophobics $^{\text {MeOH insoluble }}$ & 1023 & 114 & 89 \\
MTBE soluble & 458 & 120 & 74 \\
Lignin & 47 & 17 & 64 \\
\hline
\end{tabular}

'According to ash analyses.

The results of the TOC analyses (Fig 3) were in line with the results of the quantitative gravimetric analysis. As expected, the organic material in the hydrophilic fraction was more biodegradable than that in the hydrophobic fraction, with 94 and 84\% removal of TOC, respectively.

The impurities in isolated lignin samples were determined by analyses of carbohydrates (Fig 4) and extractives (Fig 5). The carbohydrate analyses demonstrated that the lignin samples contained small amounts of sugars. The PTE lignin contained 1.9\% carbohydrates, mostly glucose units. The FTE lignin contained as little as $0.1 \%$, and lignin isolated from sludge $1.3 \%$ carbohydrates. The extractives analysis of the PTE lignin fraction on a short column indicated that the sample contained $13 \%$ extractives, mainly comprising lignans; more detailed analysis using a long column suggested this to be mainly conidendric acid. GC analyses on a short column of the lignin fractions from FTE and sludge showed small amounts of extractives, 0.7 and $1.2 \%$, respectively.

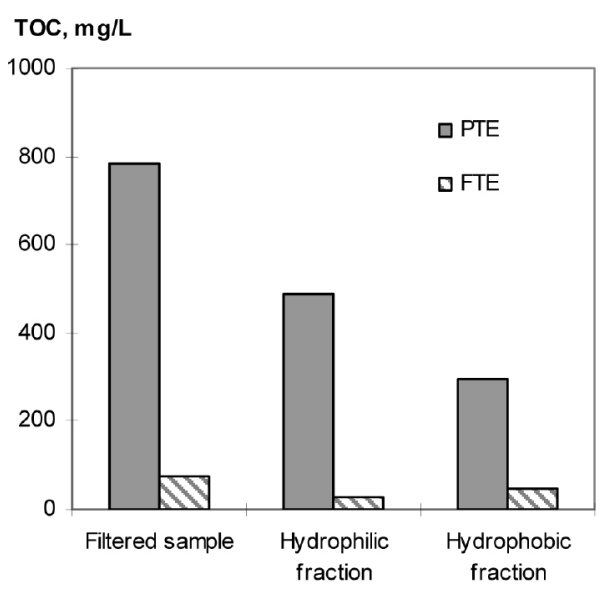

Fig 3. The TOC content of filtered samples of primary-treated effluent (PTE), finally-treated effluent (FTE), and their hydrophilic and hydrophobic fractions. The hydrophobic fraction is calculated as the difference between the filtered sample and the hydrophilic fraction.

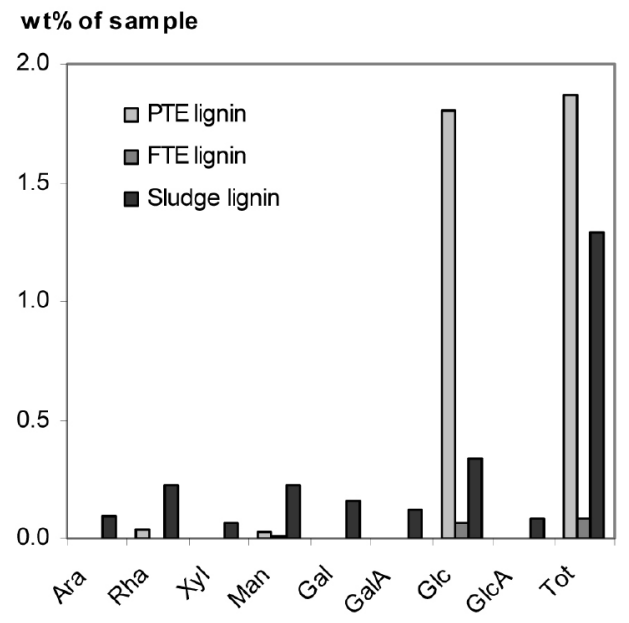

Fig 4. Carbohydrates in lignin samples analysed by GC after methanolysis. Sample notations: primary-treated effluent (PTE), finally-treated effluent (FTE), and sludge. Abbreviations: arabinose (Ara), rhamnose (Rha), xylose (Xyl), mannose (Man), galactose (Gal), galacturonic acid (GalA), glucose (Glc), and glucuronic acid (GlcA).

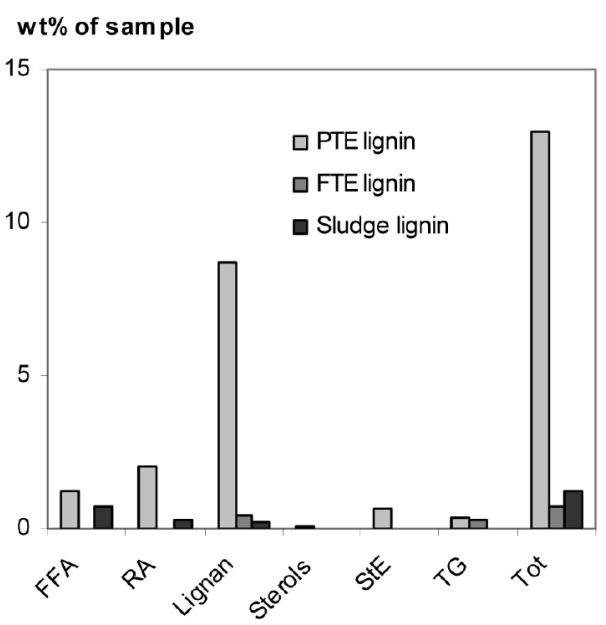

Fig 5. Extractive groups in lignin samples analysed by GC using a short column. Sample notations: primary-treated effluent (PTE), finally-treated effluent (FTE), and sludge. Abbreviations: free fatty acids (FFA), resin acids (RA), steryl esters (StE), and triglycerides $(\mathrm{TG})$.

\section{Molar mass distribution}

The molar mass characteristics of the isolated lignin samples were determined by means of Aq-SEC and $1 \mathrm{H}$ PFG NMR self-diffusion measurements. The three lignin samples differed in weight-average molar mass $\left(M_{w}\right)$ and 
number-average molar mass $\left(M_{n}\right)$ (Table 2). FTE lignin exhibited a higher average molar mass than did PTE lignin, having $M_{w}$ values of 2300 and $1500 \mathrm{~g} / \mathrm{mol}$, respectively, according to the Aq-SEC analyses. NMR analyses found similar $M_{w}$ values of $1760 \mathrm{~g} / \mathrm{mol}$ for PTE lignin and $2460 \mathrm{~g} / \mathrm{mol}$ for FTE lignin, corresponding to an average number of phenyl propane units of 10 and 14, respectively. The increase in size suggests that lowmolar-mass compounds are removed by degradation or sorption mechanisms, leaving the high-molar-mass compounds dissolved in the water. The difference in size can also be explained by biological processes condensing the lignin-like material, thereby increasing the molar mass. Ganczarczyk and Obiaga (1973) suggest experimental evidence of degradation of low-molar-mass fractions as well as chemical condensation into larger molecules during biological treatment of effluents.

Table 2. Weight-average molar mass $\left(M_{w}\right)$, number-average molar mass $\left(M_{n}\right)$, and polydispersity $\left(\mathrm{M}_{w} / \mathrm{M}_{\mathrm{n}}\right)$ of lignin fractions analysed by Aq-SEC and ${ }^{1} \mathrm{H}$ PFG NMR self-diffusion measurements. Sample notations: primary-treated effluent (PTE), finally-treated effluent (FTE), and sludge.

\begin{tabular}{|c|c|c|c|c|c|c|}
\hline \multirow[t]{2}{*}{ Sample } & \multicolumn{3}{|c|}{ Aq-SEC analysis } & \multicolumn{3}{|c|}{${ }^{1} \mathrm{H}$ PFG NMR self-diffusion analysis } \\
\hline & $\begin{array}{c}\mathbf{M}_{\mathrm{w}} \\
\mathrm{g} / \mathrm{mol}\end{array}$ & $\begin{array}{c}\mathbf{M}_{\mathrm{n}} \\
\mathrm{g} / \mathrm{mol}\end{array}$ & $M_{w} / M_{n}$ & 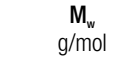 & $\underset{\mathrm{g} / \mathrm{mol}}{\mathbf{M}_{\mathrm{n}}}$ & $M_{w} / M_{n}$ \\
\hline PTE lignin & 1500 & 1300 & 1.22 & 1760 & 1350 & 1.30 \\
\hline FTE lignin & 2300 & 1800 & 1.30 & 2460 & 1760 & 1.40 \\
\hline Sludge lignin & 3000 & 2100 & 1.41 & 5460 & 2330 & 2.34 \\
\hline
\end{tabular}

The results of ${ }^{1} \mathrm{H}$ PFG NMR self-diffusion measurements shown in Table 2 and Fig 6 support the findings of a varying molar mass and show similar results as Aq-SEC for both PTE and FTE lignin. However, for the sludge lignin, deviations could be observed. In the interpretation of the NMR self-diffusion data, it was noticed that the sludge sample displayed indications of bimodal (paucidisperse) distribution, which could not be detected from the Aq-SEC data. By careful analysis of the proton signals in the aromatic region, the mass-weighted median self-diffusion coefficient was determined to be somewhat higher than what could be noticed from the analysis of the proton signals in the aliphatic region; i.e. the sample had a lower mass-weighted median molar mass if only the signals from the aromatic protons were considered. Thus, in the case of sludge lignin, the following lognormal fitting procedure of the signal intensity decays, originating from the protons belonging to the aromatic region as well as the aliphatic region, indicated a considerably higher polydispersity than what could be determined from the Aq-SEC analysis. This is a drawback whenever intensity decay data from two different distributions are used in the same dataset and gives thereby, to some extent, an overestimation of the polydispersity index. Nevertheless, the data from the ${ }^{1} \mathrm{H}$ PFG NMR measurements reveals subtle discrepancies in the molecular mass distribution that may be seen as complementary to the results obtained from the Aq-SEC analysis.

\section{Chemical characterisation}

The absorptivity of UV radiation at $280 \mathrm{~nm}$ was determined for lignin samples, indicating that the absorptivity

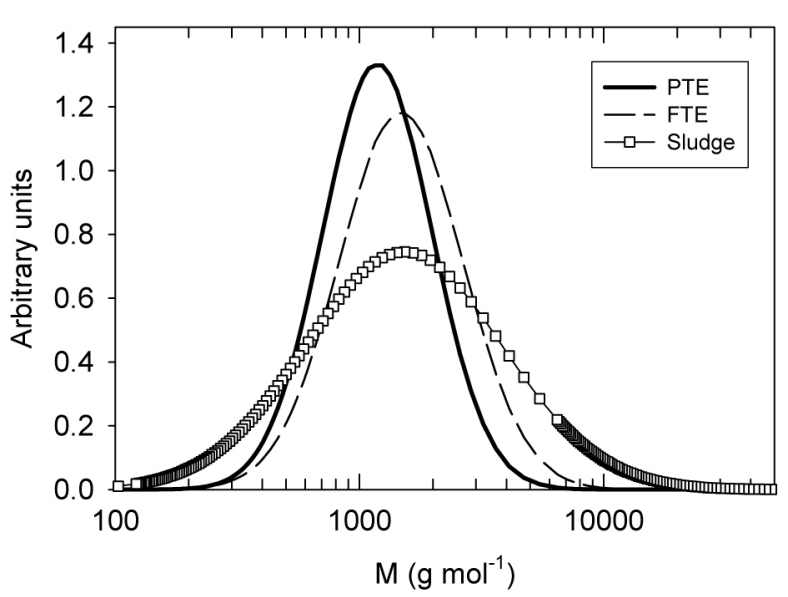

Fig 6. Mass-weighted molar mass distributions obtained from ${ }^{1} \mathrm{H}$ PFG NMR selfdiffusion measurements of the different lignin samples in aqueous solutions. Sample notations: primary-treated effluent (PTE), finally-treated effluent (FTE), and sludge.

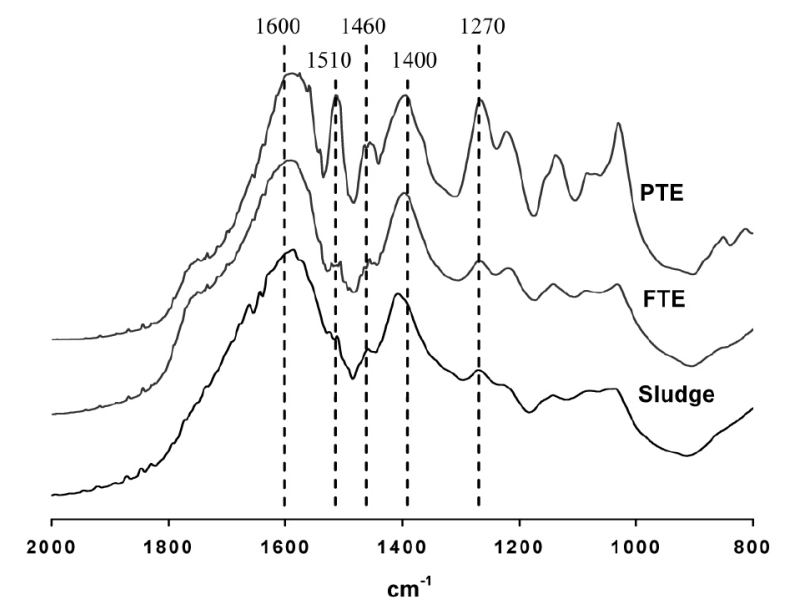

Fig 7. FTIR spectra of lignin fractions from primary-treated effluent (PTE), finallytreated effluent (FTE), and sludge.

coefficient of PTE lignin $\left(0.0129 \mathrm{l} \cdot \mathrm{mg}^{-1} \cdot \mathrm{cm}^{-1}\right)$ was higher than that of FTE lignin $\left(0.0113 \mathrm{l} \cdot \mathrm{mg}^{-1} \cdot \mathrm{cm}^{-1}\right)$. The difference in absorption suggests a change in chemical structure.

The chemical character of the isolated lignin fractions was investigated using FT-IR spectrometry. Similar absorption bands, although of different intensities, could be seen in the spectra (Fig 7).

The spectrum of PTE lignin resembled previously published spectra derived from FT-IR of milled wood lignin from spruce (Pranovich et al. 2005; Faix 1991; Fengel and Wegener 1989), and displayed even closer similarities to isolated bleached TMP lignin, as reported by Pranovich et al. (2005). The absorption bands at 1510 and $1270 \mathrm{~cm}^{-1}$ are typical of guaiacyl lignin, the first assigned to aromatic skeleton vibrations and the latter to guaiacyl ring breathing (Faix 1991; Hergert 1971). In the case of bleached TMP lignin, the intense peak at 1600 $\mathrm{cm}^{-1}$ is likely due to the overlapping of $\mathrm{C}=\mathrm{O}$ stretching from carboxylate, as pointed out by Pranovich et al. (2005). The absorption band seen at $1460 \mathrm{~cm}^{-1}$ is assigned to $\mathrm{C}-\mathrm{H}$ bonds, including methoxyl groups (Hergert 1971). The intense band at $1400 \mathrm{~cm}^{-1}$, seen in all three samples, is not reported in milled wood lignin from spruce 
(Pranovich et al. 2005; Faix 1991; Fengel and Wegener 1989). According to a study of bleached TMP lignin by Pranovich et al. (2005), the broadening of this band is due to the presence of carboxylic groups.

By comparing the spectra of PTE lignin and of biologically treated lignin in FTE and in sludge, it is obvious that biological treatment alters the chemical structure of lignin. The typical bands for guaiacyl lignin at 1510 and at $1270 \mathrm{~cm}^{-1}$ were dominant in PTE lignin but only moderate in intensity in FTE and sludge lignin. This indicates that the guaiacyl type structure is not dominant in the biologically treated lignin. The band at $1460 \mathrm{~cm}^{-1}$ was weaker in FTE lignin than in biologically treated lignin, suggesting a loss of methoxyl groups from the guaiacyl structure.

The chemical structure of the isolated lignin fractions was further investigated by pyrolysis coupled with gas chromatography and mass spectrometry (Py-GC-MS). The pyrograms of lignin-related substances from PTE and FTE are shown in Fig 8. Table 3 lists the dominant peaks identified by MS, and Fig 9 shows the structures of the identified dominant fragments.

The pyrogram of PTE lignin indicated the typical lignin fragments found in spruce milled wood lignin, viz guaiacol and aromatics with a guaiacyl moiety, for example 4-methyl guaiacol, 4-vinyl guaiacol, isoeugenol, vanillin, homovanillin, and coniferyl alcohol (Helmreich et al. 2001; Galletti and Bocchini 1995; Meier and Faix 1992). The vinyl, ethyl, or methyl substituents identified in the fragments are residues of the propanoic chains present in the original lignin molecules (Helmreich et al. 2001; Galletti and Bocchini 1995). The peak pattern from the PTE sample was analogous to the results for bleached TMP lignin (Pranovich et al. 2005). The similarities were also further supported by the ${ }^{13} \mathrm{C}$ NMR analysis, according to which sharp peaks for the PTE lignin at 27, 48, and $72 \mathrm{ppm}$, and broader signals in the rage 110-150 and 170-180 ppm ranges, coincided with the peaks for bleached TMP reported in the former study.

The pyrogram of lignin isolated from sludge indicated an intense peak identified as indole; this was likely derived from the protein tryptophan (Galletti and Bocchini 1995). Such structures might also contribute to the bimodal/paucidisperse appearance of the size distribution of the sludge sample, as was indicated by the results of the NMR self-diffusion evaluation described in the previous section. Only a few peaks in PTE and FTE lignin were identified as impurities of non-lignin origin, such as carbohydrates and proteins (Table 3).

Comparing the fragmentation patterns of PTE and biologically treated lignin indicates a shift towards compounds such as phenol and cresol in FTE lignin. These fragments differ from the guaiacyl-type units in PTE lignin by the loss of a methoxyl substituent, which also can be seen in the differences in the internal proportions of the guaiacyl-type and p-hydroxyphenyltype units of the lignin samples (Table 4). The peaks for coniferaldehyde and coniferyl alcohol, found in PTE lignin, were absent in FTE lignin, indicating that these structures had been altered. The pyrogram of lignin isolated from sludge displayed similarities to that of FTE

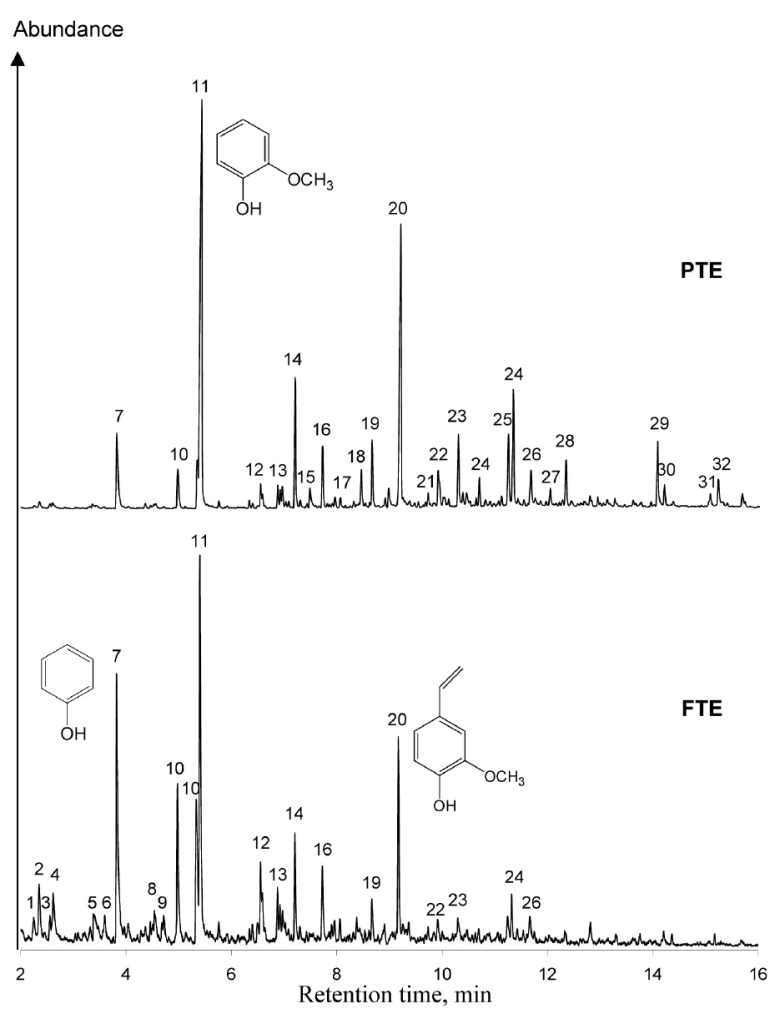

Fig 8. Pyrograms of lignin isolated from primary-treated effluent (PTE) and finallytreated effluent (FTE) with the chemical structures of peaks 7, 11, and 20. Peak numbers refer to Table 3 .

Table 3. Compounds from pyrolysis-GC-MS. Origin of compounds according to Galletti and Bocchini (1995). C: carbohydrates, P: proteins, L-H: lignin-P-hydroxyphenyl, L-G: lignin-guaiacyl.

\begin{tabular}{|c|c|c|}
\hline Peak No. & Peak identified as & Origin \\
\hline 1 & Ethylbenzene & \\
\hline 2 & Xylene & \\
\hline 3 & Styrene & $P$ \\
\hline 4 & 2-cyclopenten-1-one, 2-methyl- & C \\
\hline 5 & 2-cyclopenten-1-one, 3-methyl- & \\
\hline 6 & Aniline & \\
\hline 7 & Phenol & L-H \\
\hline 8 & 2-cyclopenten-1-one, 2,3-dimethyl- & \\
\hline 9 & Indene & \\
\hline 10 & Cresol & \\
\hline 11 & Guaiacol & $L-G$ \\
\hline 12 & Phenol, dimethyl- & $\mathrm{L}-\mathrm{H}$ \\
\hline 13 & p-Ethylphenol & $\mathrm{L}-\mathrm{H}$ \\
\hline 14 & Methylguaiacol & $L-G$ \\
\hline 15 & Catechol & \\
\hline 16 & 4-Vinylphenol & $\mathrm{L}-\mathrm{H}$ \\
\hline 17 & Ethylcresol & \\
\hline 18 & Methylcatechol & \\
\hline 19 & Ethylguaiacol & $L-G$ \\
\hline 20 & Vinylguaiacol & $L-G$ \\
\hline 21 & Chaviol & \\
\hline 22 & Eugenol & $L-G$ \\
\hline 23 & Vanillin & $L-G$ \\
\hline 24 & Isoeugenol & $L-G$ \\
\hline 25 & Homovanillin & $L-G$ \\
\hline 26 & Guaiacylethanone & \\
\hline 27 & 1-Guaiacyl-2-propen-1-ol & \\
\hline 28 & Guaiacylacetone & $L-G$ \\
\hline 29 & Dihydroconiferyl alcohol & \\
\hline 30 & 2-naphthalenol, 3-Methoxy- & \\
\hline 31 & Coniferylaldehyde & $L-G$ \\
\hline 32 & Coniferyl alcohol & $L-G$ \\
\hline
\end{tabular}


Table 4. Ratios of guaiacyl-type $(\mathrm{G})$ and p-hydroxyphenyl-type $(\mathrm{H})$ units of the lignin isolated from primary-treated effluent (PTE), finally-treated effluent (FTE), and sludge.

\begin{tabular}{lc}
\hline & Ratio of G- and H-type lignin \\
\hline PTE lignin & 4.3 \\
FTE lignin & 1.1 \\
Sludge lignin & 0.4 \\
\hline
\end{tabular}

7<smiles>Oc1ccccc1</smiles>

22<smiles>C=CCc1ccc(O)c(OC)c1</smiles>

11<smiles>C=Cc1ccc(O)c(OC)c1</smiles>

Fig 9. Chemical structure of phenol (7), cresol (10), guaiacol (11), vinylguaiaco (20), eugenol (22), vanillin (23), homovanillin (25), and coniferyl alcohol (32) (Galletti and Bocchini 1995). Numbers refer to Table 3.

lignin, having dominant peaks identified as phenol and cresol. The differences between the lignin fractions before and after biological treatment, here seen as a change in fragmentation pattern, suggest that lignin-related substances are susceptible to oxidation, and at least partial biological degradation.

Thermally-assisted hydrolysis and methylation (THM) was also used on the lignin samples in order to gain more structural information. The use of TMAH enables pyrolysis at a lower temperature (Challinor 2001; Hardell and Nilvebrant 1996), thus decreasing the formation of new compounds by thermal degradation and secondary reactions, which at conventional pyrolysis temperatures may lead to incorrect conclusions regarding the chemical structure of the polymer under study (Saint-Jimenez 1994). Methylation also enables the detection of carboxylic acids that otherwise, in conventional pyrolysis, would be eliminated by decarboxylation (Saiz-Jimenez 1994; Martin et al. 1995). Hardell and Nilvebrant (1996) report 1 -veratrylglycerol trimethyl ethers, obtained from $\beta$-ether linked units, as the main degradation products formed from lignins by THM, and the identification of such peaks also in the present experiment verified the lignin origin ( $\beta-\mathrm{O}-4$ ether bonds) of the investigated samples. The THM pyrograms also indicated that the proportion of carboxylic acids, detected as methyl esters (Hardell and Nilvebrant 1996; Challinor 1995; Martin et al. 1995), was higher in the FTE and sludge lignin samples than in the PTE lignin. This indicates that the biological treatment increases the amount of compounds containing carboxylic acids groups, by means of oxidation reactions. It may also indicate the occurrence of autoxidation reactions in the alkaline environment during pyrolysis in the presence of TMAH (Hardell and Nilvebrant 1996).

\section{Conclusion}

From the gravimetric results of effluent fractionation, it may be concluded that refractory lignin-related material contributes significantly to the residual COD in treated wastewater, and that improved removal of this material is necessary to reduce the discharge of oxygen-consuming substances.

Chemical characterisation of isolated hydrophobic material - here referred to as lignin-related material revealed properties typical of lignin. GC analyses, used to determine the carbohydrate and extractives content, confirmed a satisfying purity of isolated material. Adsorption chromatography thus appears to be a reliable method for quantitative separation of pure and unaltered lignin-related material from effluent samples. The chemical character of lignin-related material isolated from effluent before biological treatment suggests that bleaching effluent was the major contributor of lignin in the mixed effluent.

It was established that biological treatment had altered the chemical structure and size distribution of lignin-related material. Even though bioremediation may not be complete, chemical modifications still occur, discarding functional groups and aliphatic side chains. A loss of guaiacyl moieties was evident in biologically treated dissolved lignin, and in lignin adsorbed to sludge. Demethoxylation of the lignin building blocks was suggested and it was further implied that the average molar mass of lignin-related substances was increased by biological treatment. It is, however, unclear whether the average molar-mass distribution was changed due to condensation reactions or removal of the smallest dissolved compounds.

\section{Acknowledgements}

This work was financially supported by the Knowledge Foundation through the FSCN Industrial Mechanical Pulp Research College at the Mid Sweden University. We wish to thank Markku Reunanen for help with Py-GC-MS analysis (Åbo Akademi University) and colleagues from the SCA R\&D Centre for their skilful technical assistance. This work is part of the activities at the Åbo Akademi Process Chemistry Centre within the Finnish Centre of Excellence Programme (2000-2011) by the Academy of Finland.

\section{Literature}

Challinor, J.M. (2001): Review: the development and applications of thermally assisted hydrolysis and methylation reactions, J. Anal. Appl. Pyrolysis, 61(1-2), 3-34.

Challinor, J.M. (1995): Characterisation of wood by pyrolysis derivatisation-gas chromatography/mass spectrometry, J. Anal. Appl. Pyrolysis, 35(1), 93-107.

Ekman, R. and Holmbom, B. (1989): Analysis by gas chromatography of the wood extractives in pulp and water samples from mechanical pulping of spruce, Nord. Pulp Paper Res. J. 4(1), 16-24.

Faix, 0. (1991): Classification of lignins from different botanical origins by FT-IR spectroscopy, Holzforschung 45 (Suppl.), 21-27.

Fengel, D. and Wegener, G. (1989): Wood Chemistry, Ultrastructure, Reactions, Walter de Gruyter, Berlin, pp. 132-181, 417.

Fleischer, G. (1985): Effect of polydispersity on measuring polymer self-diffusion with the NMR pulsed field gradient technique, Polymer, 26(11), 1677-1682.

Franta, J., Helmreich, B., Pribyl, M., Adamietz, E. and Wilderer, P.A. (1994): Advanced biological treatment of paper mill wastewaters: Effects of operation 
conditions on COD removal and production of soluble organic compounds in activated sludge systems, Wat. Sci. Technol. 30(3), 199-207.

Galletti, G.C. and Bocchini, P. (1995): Pyrolysis/gas chromatography/mass spectrometry of lignocellulose, Rapid Commun. Mass Spectrom. 9(9), 815-826.

Ganczarczyk, J. and Obiaga, T. (1973): Mechanisms of lignin removal in activated sludge treatment of pulp mill effluents, Water Res. 8(11), 857-862.

Garver, T.M. and Callaghan, P.T. (1991): Hydrodynamics of kraft lignin, Macromolecules, 24(2), 420-430.

Håkansson, B., Nydén, M. and Söderman, 0. (2000): The influence of polymer molecular-weight distribution on pulsed field gradient nuclear magnetic resonance self-diffusion, Colloid Polym. Sci. 278(5), 399-405.

Hardell, H.L. and Nilvebrant, N.0. (1996): Analytical pyrolysis of spruce milled wood lignins in the presence of tetramethylammonium hydroxide, Nord. Pulp Paper Res. J. 11(2), 121-126.

Helmreich, B., Schiegl, C. and Wilderer, P.A. (2001): Fate of lignin in the process of aerobic biological treatment of paper mill wastewater, Acta Hydrochim. Hydrobiol. 29(5), 296-300.

Hergert, H.L. (1971): Infrared spectra, In: Sarkanen, K.V. and Ludwig, C.H. (eds.), Lignins: Occurrence, Formation, Structure and Reactions, John Wiley \& Sons, New York, pp. 267-297.

Holmbom, B., Konn, J. and Pranovich, A. (2005): What is the true yield of TMP and CTMP? What is lost in refining and bleaching? Proceedings International Mechanical Pulping Conference, Oslo, June 7-10, 98-101.

Hoque, E. (1995): High-performance size exclusion chromatographic characterization of water-soluble polymeric substances produced by Phanerochaete chrysosporium from free and wheat cell wall bound 3,4-dichloroaniline, J. Chromatogr. A 708(2), 273-281.

International Organization for Standardization, ISO 1762:2001.

Jansson, M.B. (1980): Chemistry of fiber building board mill effluent before and after biological treatment, Tappi, 63(7), 78-80.

Kringstad K.P. and Lindström, K. (1984): Spent liquors from pulp bleaching, Environ. Sci. Technol. 18(8), 236A-248A.

Levine, A.D., Tchobanoglous, G. and Asano, T. (1985): Characterization of the size distribution of contaminants in wastewater: treatment and reuse implications, J. Water Pollut. Con. F. 57(7), 805-816.

Lin, S.Y. (1992): Ultraviolet spectrophotometry, In: Lin, S.Y. and Dence, W.C. (eds.), Methods in Lignin Chemistry, Springer-Verlag, Berlin, pp. 217-232.

Lindholm, C-A. (1999): Bleaching, In: Sundholm, J. (ed.), Mechanical Pulping, Fapet Oy, Helsinki, pp. 311-342.

Magnus, E., Carlberg, G.E. and Hoel, H. (2000): TMP wastewater treatment, including a biological high-efficiency compact reactor: removal and characterisation of organic components, Nord. Pulp Paper Res. J. 15(1), 29-36.

Manner, H., Reponen, P., Holmbom, B. and Kurdin, J.A. (1999): Environmental impacts of mechanical pulping, In: Sundholm, J. (ed.), Mechanical Pulping; Fapet Oy, Helsinki, pp. 375-393.

Martin, F., del Rio, J.C., González-Vila, F.J. and Verdejo, T. (1995): Thermally assisted hydrolysis and alkylation of lignins in the presence of tetra-alkylammonium hydroxides, J. Anal. Appl. Pyrolysis, 35(1), 1-13.

Meier, D. and Faix, 0. (1992): Pyrolysis-gas chromatography-mass spectrometry. In: Lin, S.Y. and Dence, W.C. (eds.), Methods in Lignin Chemistry, SpringerVerlag, Berlin, pp. 177-199.

Pokhrel, D. and Viraraghavan, T. (2004): Treatment of pulp and paper mill wastewater: a review, Sci. Total Environ. 333(1-3), 37-58.

Pranovich, A.V., Reunanen, M., Sjöholm, R. and Holmbom, B. (2005): Dissolved lignin and other aromatic substances in thermomechanical pulp waters, J. Wood Chem. Technol. 25(3), 109-132.

Pranovich, A.V., Sundberg, K.E. and Holmbom, B. (2003): Chemical changes in thermomechanical pulp at alkaline conditions, J. Wood Chem. Technol. 23(1), $89-112$.

Rintala J.A. and Puhakka, J.A. (1994): Anaerobic treatment in pulp and paper mill waste management: a review, Bioresour. Technol. 47(1), 1-18.

Saiz-Jimenez, C. (1994): Analytical pyrolysis of humic substances: pitfalls, limitations, and possible solutions, Environ. Sci. Technol. 28(11), 1773-1780.

Smook, G.A. (2002): Handbook for Pulp and Paper Technologists, 3rd ed., Angus Wilde Publications, Vancouver, BC, pp. 6, 45, 381-397.

Springer, A.M. (1993): Bioprocessing of pulp and paper mill effluents: past, present and future, Paperi Puu, 75(3), 156-161.

Sundberg, A., Sundberg, K., Lillandt, C. and Holmbom, B. (1996): Determination of hemicelluloses and pectins in wood and pulp fibres by acid methanolysis and gas chromatography, Nord. Pulp Paper Res. J. 11(4), 216-219, 226.

Swedish Standards Institution, SS-EN 1484:1997

Thompson, G., Swain, J., Kay, M. and Forster, C.F. (2001): The treatment of pulp and paper mill effluent: a review, Bioresour. Technol. 77(3), 275-286.

Thornton, J. (1993): Dissolved and Colloidal Substances in the Production of Wood-containing Paper. Ph.D. thesis, Åbo Akademi, Turku/Åbo, Finland.

Widsten, P. and Laine, J.E. (2003): Seasonal variations in the composition and behaviour in biological treatment of an effluent from an integrated pulp and paper mill, Nord. Pulp Paper Res. J. 18(2), 158-161.

Örså, F. and Holmbom, B. (1994): A convenient method for the determination of wood extractives in papermaking process waters and effluents, J. Pulp Pap. Sci. 20(12), J361-J366. 